\title{
CLARICE LISPECTOR: ARTISTA ANDRÓGINA OU ESCRITORA?
}

\author{
POR \\ MARIA LUISA NUNES \\ University of Pittsburgh
}

Clarice Lispector teve a ventura de viver e escrever no século vinte. No A Room of One's Own, Virginia Woolf nos conta que o destino da artista dos séculos passados era ser acusada e castigada como santa, feiticeira, louca ou puta. Se examinamos a fundo o corpo de ficção de Clarice Lispector - A Maçã no Escuro (1961), A Paixão Segundo G. H. (1964), Uma Aprendizagem (1969), A Hora da Estrela (1977) ${ }^{1}$ - ouvimos entre suas criaturas ecos das categorias que Virginia Woolf citou. Porque Clarice vê as buscas dos seus personagens como atos de criação e, portanto, considera suas criaturas como artistas - «Ele por enquanto estava se moldando, e isso é sempre lento: ele estava dando forma ao que êle era, a vida se fazendo era difícil como arte se fazendo» (ME, p. 111) — pode-se dizer que as preocupações dos personagens são compartilhadas por ela. Estando a par de algumas delas, é lícito assumir que a identidade particular da artista é de grande importância para Clarice Lispector.

Apesar de ter negado preocupações feministas ${ }^{2}$, a autora deixa transparecer o problema da sorte da mulher em suas obras: «O destino de uma mulher é ser mulher» (HE, p. 101). O que surpreende nesta época de conscientização é que a maior parte da crítica de Clarice Lispector tenha

${ }^{1}$ Clarice Lispector, A Maça no Escuro, 3., edição (Rio de Janeiro: J. Alvaro, Editor, 1970); íd., A Paixão Segundo G. H., 4. ${ }^{a}$ edição (Rio de Janeiro: Livraria José Olympio Editôra, 1974); íd., Uma Aprendizagem ou O Livro dos Prazeres, 3. ${ }^{a}$ edição (Rio de Janeiro: Sabiá, 1973); íd., A Hora da Estrela, 3. ${ }^{a}$ edição (Rio de Janeiro: Livraria José Olympio Editôra, 1978). References to these works will be abreviated in the text as: $M E, P S G H, U A$ and $H E$.

${ }^{2}$ Interview, Rio de Janeiro, July, 1976. 
sido feita por homens ${ }^{3}$. Entre as mulheres que escreveram sobre suas obras ${ }^{4}$, ao que eu saiba, nenhuma até agora empregou uma abordagem feminista ao tratar a questão da matriz ou da personalidade feminina em relação à escritora. Em realidade, as observações críticas ressaltam que se trata de alguma coisa fora do vulgar. Fábio Lucas, por exemplo, declarou: «Clarice Lispector já surgiu como um caso estranho no cenário brasileiro» ${ }^{5}$. Outro crítico indicou que $A$ Paixão Segundo $G$. $H$. bem poderia ser sua representação de um sistema de delusões ${ }^{6}$. Loucura ou misticismo? Na opinião de Antônio Cândido, «ela abria novos caminhos à expressão verbal que conseguiram estender o domínio da palavra sobre regiões mais complexas e mais inexprimíveis, ou fazer da ficção uma forma de conhecimento do mundo e das idéias» ${ }^{7}$. Benedito Nunes assinala sua inovação da densidade psicológica, a maneira descontínua de narrar, a força poética ${ }^{8}$.

Está claro que os críticos acham que o fato de Clarice ser mulher seja irrelevante numa análise do seu trabalho, o que talvez seja louvável. Contudo, a questão da identidade da artista, ou de como uma mulher difere dum homem ao escrever, é de muito interesse atual. Enquanto Virginia Woolf está a favor da androginia, tais elementos da voz feminina, como um passo lento, uma prosa arrumada e ordeira parecem assinalar uma revalorização de identidade feminina ou integridade sobre androginia.

Neste ensaio, procurarei uma resposta à pergunta: artista andrógina ou escritora? $\mathrm{O}$ primeiro obstáculo que encontro ao abordar esse problema é uma proibição de formar juízos na base de conteúdo. Em todos os romances analisados, menos em $A$ Maçã no Escuro, os sujeitos são mulhe-

${ }^{3}$ Benedito Nunes, Clarice Lispector (São Paulo: Edições Quirón, 1973); Antônio Cândido, «No raiar de Clarice Lispector», em Vários escritos (São Paulo: Livraria Duas Ciudades, 1970); Fábio Lucas, "Clarice Lispector e o impasse da narrativa contemporânea», em Poesia e prosa no Brasil (Belo Horizonte: Interlivros, 1976); Earl Fitz, "Clarice Lispector and the Lyrical Novel: A Re-examination of $A$ Maçã no Escuro», em Luso-Brazilian Review, vol. 14, núm. 2 (Winter, 1977), pp. 153-160; Dennis Seniff, «Self Doubt in Clarice Lispector's Laços de familia», em Luso-Brazilian Review, vol. 14, núm. 2 (Winter, 1977), pp. 161-173. See the bibliography of Clarice Lispector in the present edition of $R I$ for others.

"Rita, Herman, «Existence in Laços de familia», em Luso-Brazilian Review, vol. 4, núm. 1 (Spring, 1967), pp. 69-74; M. Luisa Nunes, «Narrative Modes in Clarice Lispector's Laços de familla: The Rendering of Consciousness», em LusoBrazilian Review, vol. 14, núm. 2 (Winter, 1977), pp. 174-184.

${ }^{5}$ Op. cit., p. 13.

${ }^{6}$ Emir Rodríguez Monegal, Interview (New Haven, June 1977).

${ }^{7}$ Op. cit., p. 126.

${ }^{8}$ Op. cit., p. XVII. 
res. Suas consciências -interioridade, sensibilidade, misticismo - indicariam uma matriz feminina. Encontro uma indicação esclarecedora na explicação de Clarice sobre a relação entre forma e conteúdo: "Por que escrevo? Antes de tudo porque captei o espírito da língua e assim às vezes a forma é que faz conteúdo. Escrevo portanto não por causa da nordestina mas por motivo grave de 'força maior', como se diz nos requerimentos oficiais, por 'força de lei'» (HE, p. 23). Por conseguinte, verifiquei na própria obra de Clarice duas diretrizes: a identificação da autora com suas criaturas e a unidade de forma e conteúdo.

Nas obras de Clarice, suas criaturas - ora homens ora mulheresfazem observações metaliterárias sobre sua arte. Para G. H., fingir escrever para alguém facilita contato com sentidos mais profundos: «Esse esforço que farei agora por deixar subir à tona um sentido, qualquer que seja, esse esforço seria facilitado se eu fingisse escrever para alguém» (PSGH, p. 12). Essa raison d'écrire não é o reino exclusivo de mulheres embora a preocupação com os sentidos seja um atributo apropriadamente feminino. Para o protagonista de Uma Aprendizagem, o escrever ou a arte é permeado de mistério, de miraculoso e de aventura. Exige muita coragem, dedicação e humildade - humildade sem perder o enfoque de si como centro do mundo em contraste com a protagonista-. Aqui, a expectativa de comportamento segundo os sexos é realizada. Ulisses, o filósofo, não possui uma «consciência infeliz» enquanto Lori é o oposto feminino. Ela não é o centro do seu mundo. Por outro lado, o narrador de A Hora da Estrela parece não ter vontade de continuar se não fosse escrever, sua única raison d'être. "Escrevo porque sou um desesperado e estou cansado, não suporto mais a rotina de me ser e se não fosse a sempre novidade que é escrever, eu me morreria simbolicamente todos os dias» (HE, p. 27). Acrescenta que não lê nada para não contaminar a simplicidade da sua linguagem.

Seguindo o rumo do metaliterário, Ulisses de Uma Aprendizagem observa que a realidade é a matéria prima, a linguagem, o modo de prosurá-la, e o fracasso de sua linguagem the dá o indizível (UA, pp. 212, 213). Em síntese, as observações sobre arte feitas pelos personagens e narradores de Clarice - a revelação de sentidos, o mistério, o milagre, a aventura de escrever, escrever como raison d'être e um elo com a identidade e com o metafísico- assinalam uma postura artística em vez de a criação de uma mulher. Mas voltemos nossa atenção à linguagem de Clarice.

Acima de tudo, Clarice Lispector é uma inovadora lingüística. Segundo Antônio Cândido: 
A autora colocou sèriamente o problema do estilo e da expressão. Sobretudo desta. Sentiu que existe uma certa densidade afetiva e intelectual que não é possível exprimir se não procuramos quebrar os quadros da rotina e criar imagens novas, novos torneios, associações diferentes das comuns e mais fundamente sentidas. A descoberta do quotidiano é uma aventura sempre possível, e seu milagre uma transformação que abre caminho para mundos novos (...). Clarice Lispector aceita a provocação das coisas à sua sensibilidade e procura criar um mundo partindo das suas próprias emoções, das sua própria capacidade de interpretação. Para ela, como para outros, a meta é, evidentemente, buscar o sentido da vida, penetrar no mistério que cerca o homem. Como os outros, ela nada consegue, a não ser esse timbre que revela as obras de exceção e que é a melhor marcha de espírito sobre a resistência das coisas ${ }^{9}$.

Podemos acompanhar o itinerário lingüístico de Clarice na criação de Martim em $A$ Maçã no Escuro. Ele rejeita a linguagem dos outros e apenas tem os começos duma própria. Contudo, «oco, mudo rejubilava-se» (ME, p. 27). Como sua criatura, Clarice parte de uma tabula rasa lingüística para criar uma nova língua por meio da qual espera conseguir a identidade, a realidade, a verdade. A linguagem estabelecida ou a dos outros faz exigências na consciência e na liberdade de uma pessoa, percebe Martim, enquanto apalpa sua memória para descobrir que devia sentir horror do seu crime. Mas para ele, na perda ou na rejeição da linguagem, está implícita a necessidade de manufaturar aquilo que quer possuir. Sua produção, como a de Deus, seria uma verdade que não podia ver (ME, p. 31). Finalmente, não há palavra alguma para descrever o fato de «no agigantamento de si próprio, ele ter alcançado o alto da montanha» (ME, p. 41). Martim, tanto como G. H. e outras criaturas de Lispector, é destinado à derrota num mundo onde as palavras separam os humanos da realidade. Mais uma vez, um elemento do programa estético de Clarice sugere uma abordagem artística e criadora ao invés de uma determinada pelo sexo da autora. Mas consideremos seu estilo.

Através de suas criações artísticas, Clarice revela suas próprias idéias sobre o estilo, uma das quais é atingir o objetivo máximo de um escritor, escrever sem estilo: «E escreverei sem estilo, disse como se falase sozinho. Escrever sem estilo é o máximo que, quem escreve, chega a desejar» (UA, p. 171). Em A Hora da Estrela, o narrador faz questão de dizernos que sua meta é a simplicidade e seu ofício, o de um carpinteiro. Este

${ }^{9}$ Op. cit., p. 128. 
detalhe da observação - carpinteiro- faz um contraste interessante com as ocupações de algumas personagens, tal como G. H., uma escultora que tem um talento para a arrumação. Em $A$ Hora da Estrela, o ofício é enfaticamente masculino: «Pretendo, como já insinuei, escrever de modo cada vez mais simples. Aliás o material de que disponho é parco e singelo demais, as informações essas que penosamente me vêm de mim para mim mesmo, é trabalho de carpinteria» (HE, p. 19). Finalmente, Clarice alude ao sentido secreto de sua prosa que ultrapassa as palavras e as frases.

Para o crítico Benedito Nunes, a prosa da Clarice baseia-se em matrizes poéticas ou num movimento circular da palavra ao silêncio, do silêncio à palavra, numa abstração conceptual, num elevado grau de ênfase, e na repetição, um meio hábil para exprimir a paixão com mais força e mais energia ${ }^{10}$. Os aspectos retóricos que encontramos na prosa de Clarice são paronomásias, oxímorons, antíteses, e paradoxos. Os oxímorons são os mais abundantes nas suas imagens de silêncio e palavras, nos seus contrastes entre noite e iluminação, humanos e animais, brandura e ferocidade, paz e luta. A epifania na prosa de Clarice se relaciona com seu misticismo ou simplemente com o uso mais joyceano de «manchas cósmicas que substituían entender» (UA, p. 43).

E óbvio que nenhum desses aspectos per se indica a mão de uma mulher. Em $A$ Paixão Segundo G. H., porém, a unidade de forma e conteúdo indica claramente a escritora. A narradora na primeira pessoa é uma mulher. A grande concentração de verbos na sua prosa, especialmente a abundância de construções gerundiais, indica o movimento contínuo de uma busca psíquica e espiritual. De fato, a comunicação através do ato de escrever, a catarse alcançada por essa experiência, e a perda de uma parte essencial de si constituem a ação do romance. Mais reveladora da feminilidade é a passagem seguinte à qual já me referi: «O quarto era o oposto do que eu criara em minha casa, o oposto da suave beleza que resultara de meu talento de arrumar, de meu talento de viver, o oposto de minha ironia serena, de minha doce e isenta ironia» (PSGH, p. 48).

$\mathrm{O}$ estilo indireto livre que abre Uma Aprendizagem igualmente sugere uma consciência feminina com seu acúmulo de detalhes domésticos sobre o apartamento, o amante, a vida social e o emprego, e cresce até chegar a meditações filosóficas e existenciais, para terminar em fantasias. $\mathrm{O}$ acúmulo de detalhes, a primeira frase longa de três páginas e a repetição de palavras tais como «histérico», «histérico», «histericamente», indicam a matriz feminina sem mais explicações. As imagens de animais também

${ }^{10}$ Op. cit., p. 123. 
são ligadas ao feminino neste romance: «animal histérico», «sua vida mais primitiva e animal», «ignorância animal» (UA, p. 12).

$\mathrm{O}$ romance posterior A Hora da Estrela, cujo narrador é um homem, emprega o pretérito em frases curtas e fortemente acentuadas. O próprio narrador comenta esse estilo: "Então eu canto alto agudo uma melodia sincopada e estridente -é a minha própria dor, eu que carrego o mundo e há falta de felicidade» (HE, p. 15). Embora a prosa sincopada e acentuada sugira o masculino, alto agudo e estridente assinalariam uma voz feminina. Expressadas por oxímorons e repetições são as preocupações metafísicas sobre origens e essências, perguntas sem respostas, a inefabilidade da existência, e o ponderar sobre a morte. É claro que a prosa deste romance é metafísica, e não determinada pelo sexo da autora. Para levar essa neutralidade até o lado feminino, é útil examinar algumas imagens de Uma Aprendizagem.

As referências de Clarice à anatonomia e às funções do corpo feminino são bastante explícitas: «E não chove, não chove. Não existe menstruação. Os ovários são duas pérolas secas. Vou vos dizer a verdade: por ódio seco, quero é isto mesmo, o que não chova» (UA, p. 22). Se esses aspectos biológicos sugerem a matriz literal, há características psicológicas que evocam o homem. Pode-se citar o falar do protagonista de Uma Aprendizagem - direto, confiante, agressivo, sem rodeios; claro na expressão de desejos sexuais. O falar, pode representar outro aspecto de desenho de personagem. Veja, por exemplo, a cartomante parodiada de A Hora da Estrela. Seu uso do diminutivo, de expressões tais como "minha flor», e a descrição que o narrador faz dela parecem criar uma mulher estereotipada.

Menos estereotipado é o jogo psicológico entre personagens masculinos e femininos em $A$ Maçã no Escuro. Vejamos como Vitória reage a Martim: «Havia homens junto dos quais uma mulher se sentia rebaixada por ser uma mulher; havia homens junto dos quais uma mulher aprumava o corpo em quieto orgulho; Vitória estava insultada pelo modo como ele a fizera aprumar a cabeça» (ME, p. 49). O caso oposto ao de Vitória é sua prima enviuvada, Ermelinda: «Um dia experimentou dizer-se uma coisa só para ver se dava certo: "quero ser o sapato que ele usa, quero ser o machado que ele pega na mão' - e depois aguardou muito atenta; e deu tão certo que, de emoção, ela abaixou os olhos modestos, confusa, escondendo como pôde um sorriso» (ME, p. 80). Essas mulheres são casos extremos, uma na sua atração relutante por Martim, a outra na sua sujeição abjeta a ele. A psique masculina é mais bem desenhada na caracterização de Francisco que mantém sua dignidade por meio do ódio que ele sente por Vitória, dominadora: 
Também este olhar Francisco recusou, fitando ostensivamente uma árvore. Aquele estranho não percebera a fidelidade de Francisco à mulher, não entendera que ele se habituara calmamente a odiar Vitória, e que não poderia ser mandado por uma mulher a não ser que salvaguardasse a própria dignidade com o ódio. E como se a mulher o tivesse entendido, jamais tentara estabelecer o menor laço de simpatia entre ambos: para Francisco esta se tornara a prova de que ela o respeitava. Do momento em que ela fosse boa, começaria a decadência dele. Ele respeitava na mulher a força com que esta não o deixava ser nada mais nem nada menos do que ele era (ME, p. 50).

Estilisticamente, a única conclusão sobre Clarice Lispector a que se pode chegar é que ela representa homens de uma maneira masculina e mulheres de uma maneira feminina, segundo certas convenções e expectativas. $\mathrm{O}$ fato de ter criado em sua maioria personagens femininos não deprecia seu status de artista, assim como o de Machado de Assis não fica comprometido por ter escrito sempre sobre o coração masculino. Porém, na prosa de Clarice a questão do comportamento masculino e feminino está presente e, na minha opinião, a autora faz opção pela androginia.

Um exemplo da androginia de Clarice ocorre no ponto de vista da narrativa de $A$ Hora da Estrela. A dedicatória do Autor (na Verdade Clarice Lispector) simboliza o homem e a mulher dentro da psique da artista. Clarice afirma a condição de andrógina por causa de preconceitos contra escritoras ao dizer: «Aliás - descubro eu agora- também eu não faço a menor falta, e até o que escrevo um outro escreveria. Um outro escritor, $\mathrm{sim}$, mas teria que ser homem porque escritora mulher pode lacrimejar piegas» (HE, p. 18). Portanto, Clarice, uma mulher, disfarça-se ligeiramente num narrador, mas o ponto central é que ambos coexistem na mente criadora, como assinalou Virginia Woolf. Outro exemplo da artista andrógina reside em G, H., a escultora, cuja vida não tem papéis femininos como limite: «Para uma mulher essa reputação é socialmente muito, e situou-me, tanto para os outros como para mim mesma, numa zona que socialmente fica entre mulher e homem. O que me deixava muito mais livre para ser mulher, já que eu não me ocupava formalmente em sê-lo» (PSGH, p. 27). Os ecos de Virginia Woolf encontram-se na declaração de G. H. de que sua liberdade resulta de ser financeiramente independente.

Simbolicamente, outras personagens de Lispector como Lóri e Ulisses completam-se numa maneira andrógina: «Ele era um homem, ela era uma mulher, e milagre mais extraordinário do que esse só se comparava à estrela-cadente que atravessa quase imaginariamente o céu negro e deixa como rastro o vívido espanto de um universo vivo. Era um homem o era 
uma mulher» (UA, p. 24). Em suas primeiras obras, Clarice preocupava-se com papéis estereotipados de homens e mulheres. Em A Maçã no Escuro, o narrador comenta sobre os milhões de homens que imitam a idéia de um homem ao lado dos milhões de mulheres que imitam a idéia de uma mulher, e os milhões de pessoas que copiam a própria idéia de existir (ME, p. 27). Essa imitação, em Martim, contrasta de certo com a odisséia aprofundadora do próprio descobrimento. Durante esse processo, Martim aprende que seu corpo não é suficiente em si: «Lembrou-se de que mulher é mais que o amigo de um homem, mulher era o próprio corpo do homem. Com um sorriso um pouco doloroso, acariciou então o couro feminino da vaca e olhou em tôrno: o mundo era masculino e feminino (ME, p. 83).

Voltando às personagens femininas de Clarice, claro está que suas preocupações metafísicas não se limitam a pessoas do mesmo sexo. Com a fragilidade física das mulheres contrasta-se o medo generalizado de ver o que é Deus (PSGH, p. 116). Apesar desse egalitarianismo, Lóri de Uma Aprendizagem é totalmente auto-depreciativa e por isso Ulisses a censura sempre. Por meio da sua aprendizagem, a união do masculino e do feminino se realiza e resolve o dilema existencial de Lóri, em sua grande parte o de ser uma mulher em desacordo com a sociedade brasileira. Quando ela pergunta a Ulisses qual é o seu valor social, ele responde: «O de uma mulher desintegrada na sociedade brasileira de hoje, na burguesia da classe média» (UA, p. 172). Essa consideração nos dirige a uma preocupação mais basicamente feminista embora Clarice, como declarei antes, negasse tê-la. Podemos talvez chamá-la de feminista malgré elle.

Em termos da libertação da mulher, há uma passagem de $A$ Paixão Segundo $G$. $H$. que atrai a atenção de qualquer feminista alienígena que tenha algum conhecimento do contexto brasileiro. A existência de empregadas domésticas indica claramente que mulheres são as exploradoras e opressoras de outras mulheres no Brasil. A narradora de A Paixão Segundo G. $H$. reflete sobre o ódio que a antiga empregada tinha por ela e o epíteto que ela deu a patroa ao desenhar na parede figuras nuas de um homem e de uma mulher na presença de um cachorro. Para a opressora, a relação é incômoda, visto que seus costumes estão sendo julgados por essa presença que quase não existia para ela. G. H. percebe que a empregada, Janair, odiava-a com o pior ódio: indiferença. No conceito que cada mulher fazia da outra não se reconhece a dignidade humana. $O$ episódio é passageiro em A Paixão Segundo $G$. H. mas muito real no contexto brasileiro.

Tanto Clarice Lispector quanto seu crítico principal, Benedito Nunes, reconhecem que os romances da autora terminam numa interrogação. Ape- 
sar de todo o seu aprofundamento linguiístico e espiritual, ainda não encontra uma resposta certa ao mistério da vida e da morte. Ao lado de um imponderável tão perene e monumental, a questão que gerou este ensaio torna-se secundária. Não obstante, como correlativa estética de preocupações políticas, á válida atualmente. 
